\title{
Using Technology to Manage Self-harm in Young People: Patients' Expectations for the Future Digital Resources
}

\author{
Anja ČUŠ ${ }^{1}$, Julian EDBROOKE-CHILDS ${ }^{2}$, Susanne OHMANN ${ }^{1}$, Paul L PLENER ${ }^{1}$, Türkan AKKAYA-KALAYCI ${ }^{1}$
}

1 Medical University of Vienna, Department of Child and Adolescent Psychiatry, Vienna, AT

2 Anna Freud National Centre for Children and Families \& University College London, London, UK

\section{BACKGROUND}

Non-suicidal self-injury (NSSI) in young people is an important mental health problem and it is associated with negative psychosocial outcomes. While recent developments in digital interventions show promise in self-harm management, they rarely include the 'voice' of young people with lived experience. This study explored what experiences do young people who engage in NSSI have with using existing online interventions and resources. It further examined what characteristics should future interventions entail to be more relevant for their needs.

\section{METHOD}

Sample: Fifteen female adolescents aged 1218 who were in contact with mental health services due to NSSI

Data collection: Individual semi-structured interviews

Data analysis: Thematic analysis (Braun \& Clarke, 2006)

\section{RESULTS}

I. Theme: Experiences of NSSI describes understanding the 'user' of the future digital resources and management of his/her NSSI

II. Theme: App in Context describes future technology-enabled resources (e.g. apps) as context dependent and entails the four subthemes below:

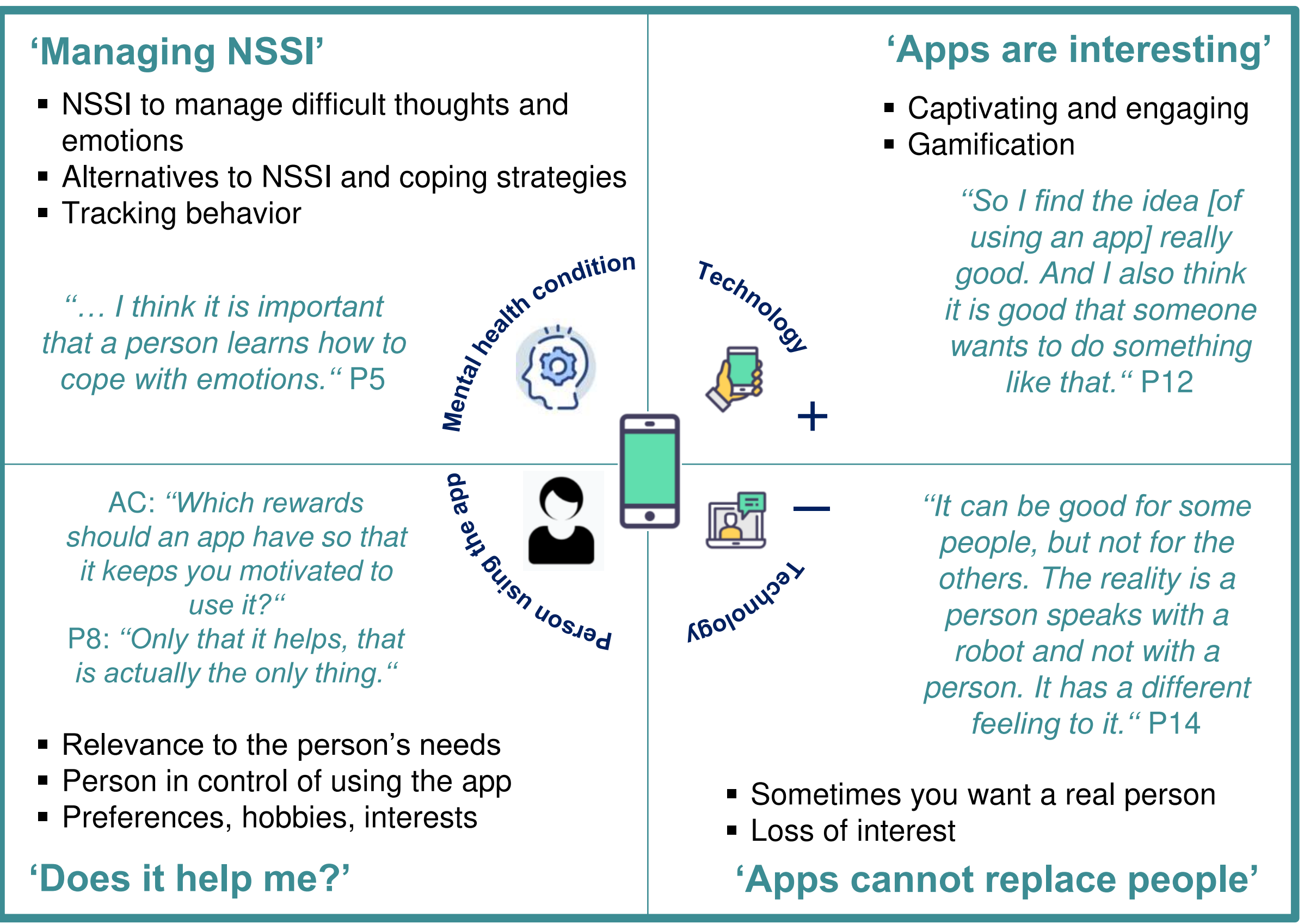

\section{CONCLUSIONS}

- Young people are interested in the future digital resources if they find them credible and relevant for their experiences and interests

- This study suggests that future digital resources need to acknowledge the diverse triggers for NSSI and provide better support especially in acute situations. Additionally, contexts-related factors need to be taken into account to improve user engagement

- Collaborations among mental health experts, humancomputer interaction professionals and people with lived experience seem necessary to improve the development of future digital resources (e.g. smartphone apps) for NSSI management

\section{ACKNOWLEDGMENTS}

TEAM (Technology Enabled Mental Health for Young People) has received funding from the European Union's Horizon 2020 research and innovation programme under the Marie SkłodowskaCurie grant agreement No. 722561

\section{CONTACT DETAILS}

ه Anja.Cus@meduniwien.ac.at uerkan.Akkaya-Kalayci@meduniwien.ac.at

in Anja Cus

y @AnjaCus

\section{REFERENCES}

Braun, V., \& Clarke, V. (2006). Using thematic analysis in psychology. Qualitative Research in Psychology, 3(2), 77-101 doi:10.1191/1478088706qp063oa

Menr, D. C. Weingrd, K. R., Redd, M. \& Schuelde, S. M. (2017). Three problens with current digital mental health research... and three things we can do about them. current digital mental health research... and three things we can

Psychiatric services, 68(5), 427-429. doi.org/10.1176/appi.ps.201600541 Stallard, P., Porter, J., \& Grist, R. (2018). Smartphone App (Bluelce) for Young People Who Self-Harm: Open Phase 1 Pre-Post Trial. JMIR Mhealth Uhealth, 6(1), e32. doi:10.2196/mhealth.8917

Icons: https://www.stockio.com/free-icons 